\title{
PENGARUH PEMBERIAN IKAN HIAS JANTAN TERHADAP JUMLAH LARVA AEDES AEGYPTI TAHUN 2015
}

Apriliyah Joshua, Koerniasari, Demes Nurmayanti

\begin{abstract}
Dengue Hemorrhagic Fever (DHF) becomes a public health problem In Indonesia due to high number of sufferers and its wide spread. Control methods have been carried out chemically and non-chemically. Use of mosquitofish is one of the biological controls in which certain types of fish used as natural enemies or predators of mosquito larvae. The purpose of this study is to determine effect of male ornamental aquarium fish to the number of Aedes aegypti larvae.

This is a quasi-experimental research carried out by conducting experiment on Betta crown tail fish and Pterophyllum altum eting ability to the number of Aedes aegypti larvae. Data used in this research is primary and secondary data. The primary data were obtained from observation during experiment of the number of Aedes aegypti larvae eaten by both types of ornamental fish, while the secondary data was data from books and journals supporting the research.

Result showed that Betta crown tail fish were the most influencing fish with an average eating ability of 282 larvae per day. While average of Pterophylum Altum eating ability was 248 larvae per day. Result of the research lead to suggestion on the use of Betta crown tail fish as predators of Aedes aegypti larvae in and medium size bath up and Pterophylum Altum fish for the tub large size one.
\end{abstract}

Keywords : Male ornamental fish, Aedes aegypti larvae

\section{Latar Belakang}

Pemberantasan vektor masih dititik beratkan pada penggunaan insektisida kimia karena efektif dan hasilnya dapat diketahui dengan cepat. Akan tetapi sebagai akibat pengunaan insektisida dalam pengendalian vektor, menyebabkan matinya musuh alami, resistensi vektor, menimbulkan pencemaran lingkungan dan mengganggu kesehatan manusia. Dengan timbulnya masalah tersebut perlu dilakukan solusi lain dalam pengendalian vektor berwawasan lingkungan yaitu pengendalian hayati atau biologi. Pemanfaatan ikan pemakan larva nyamuk adalah salah satu pengendalian nyamuk secara biologi control, dimana jenis ikan tertentu dimanfaatkan sebagai musuh alami atau predator nyamuk stadium larva.

\section{Hasil Penelitian dan Pembahasan}

REKAPITULASI DAYA MAKAN IKAN HIAS JANTAN TERHADAP JUMLAH LARVA AEDES AEGYPTI BERDASARKAN JENIS IKAN HIAS YANG DIUJI TAHUN 2015

Jenis Ikan

$\Sigma$ Larva yang dimakan

Rata-Rata $\Sigma$

Larva yang

Percobaan ke... dimakan

\begin{tabular}{lccccccc} 
& 1 & 2 & 3 & 4 & 5 & 6 & \\
\hline Betta crown tail & 150 & 138 & 148 & 135 & 146 & 132 & 142 \\
\hline $\begin{array}{l}\text { Pterophylum } \\
\text { altum }\end{array}$ & 118 & 115 & 127 & 120 & 135 & 130 & 124 \\
\hline Kontrol & 0 & 0 & 0 & 0 & 0 & 0 & 0
\end{tabular}


Media air kelompok perlakuan maupun kontrol diberi larva Aedes aegypti sebanyak 150 ekor setiap 12 jam dengan pH berkisar 7 dan suhu rata-rata $29-30^{\circ} \mathrm{C}$. Hasil yang diperoleh dari percobaan 1 hingga 6, kedua ikan hias jantan yaitu Betta crown tail dan Pterophylum altum ternyata memiliki daya makan yang berbeda-beda. Pada percobaan ke-5, terjadi perubahan perilaku ikan, ikan tersebut berenang terlalu cepat, hal ini menunjukkan ikan mengalami stress, dikarenakan terjadi kenaikan suhu pada media air hingga mencapai $31^{\circ} \mathrm{C}$. Sehingga dilakukan pergantian air untuk menghindari terjadinya stress pada ikan, sedangkan pada kelompok control juga diberi larva sebanyak 150 ekor larva dan hasilnya dari percobaan 1 sampai 6 tidak ditemukan adanya larva yang mati.

Meskipun kedua ikan tersebut merupakan predator, akan tetapi ikan Betta crown tail membuktikan memakan larva paling banyak. Hal ini tidak sesuai dengan penelitian Hijra Wati (2009) yang membandingkan ikan Cupang Hias ( Betta sp. ) dengan ikan Maanvis sebagai predator larva nyamuk, dimana ikan Maanvis lebih banyak memakan Larva nyamuk. Perbedaan hasil ini kemungkinan besar dipengaruhi oleh beberapa perbedaan yang pertama yaitu Volume air, Volume air yang diberikan kepada Betta crown tail (ikan Cupang) dengan ikan Pterophilum altum (ikan Maanvis). Pada penelitian yang dilakukan Hijra Wati (2009), tiap ikan diberi air sebanyak 1 liter sedangkan pada penelitian ini ikan Betta crown tail (ikan Cupang) 4 liter dan ikan Pterophilum altum (ikan Maanvis) 7 liter. Perbedaan yang kedua adalah Instar larva Aedes aegypti, pada penelitian Hijra wati (2009), instar larva yang di berikan tidak diketahui. Sedangkan pada penelitian ini larva Aedes aegypti yang digunakan adalah instar 2.

\section{KESIMPULAN DAN SARAN \\ Kesimpulan}

Ada pengaruh pemberian berbagai jenis ikan hias jantan terhadap jumlah larva Aedes aegypti. Ikan Betta Crown Tail mempunyai pengaruh paling besar karena memakan larva nyamuk lebih banyak dari pada ikan Pterophylum Altum dengan rata-rata daya makan ikan Betta Crown Tail adalah 142 ekor larva per 12 jam (282 ekor larva per hari) dan ikan Pterophylum Altum adalah 124 (248 ekor larva per hari).

\section{Saran}

Ikan hias dapat di jadikan salah satu alternative untuk menekan populasi nyamuk Aedes aegypti di daerah yang kurang air. Ikan Betta crown tail dapat di jadikan predator larva nyamuk Aedes aegypti di bak mandi dengan ukuran kecil dan sedang, sedangkan untuk bak mandi dengan ukuran besar dapat menggunakan ikan Pterophylum Altum. Perlu dilakukan penelitian dengan menggunakan ikan hias yang berukuran tubuh sama maupun ikan jenis yang lain.

\section{DAFTAR PUSTAKA}

Agus, dkk. 2011. Maanvis. Jakarta. Agro Media Pustaka.

Aneka Ikan Hias Tersedia dari http://quoteimq.com/red-cobraguppy/ Di Akses 13 Februari 2015 jam 20.00 WIB.

Arikunto, Suharsini, 2010. Prosedur Penelitian Suatu Pendekatan Praktek. Jakarta. Rineka Cipta.

Dini DKK. 2010. Faktor Iklim dan Angka Insiden Demam Berdarah Dengue. Surabya : Makara.

Ginanjar Genis. 2010. Apa yang Dokter Anda Tidak Katakan Tentang Demam Berdarah. Bandung : Fakultas Kedokteran.

Gunawan Henry, Prakarsa E. Bambang. 2012. Solusi Permasalahan Cupang. Depok : PT. Penebar Swadaya.

Hariningtyas Muntianingrum, 2010. Perbedaan kapasitas makan ikan manvis (petrophyllum altum), ikan sepat biru (trichogaster trichopterus) dan ikan guppy (poecilia reticulate) sebagai predator larva nyamuk aedes aegypti. Skripsi Fakultas Kesehatan Masyarakat Universitas Jember Tersedia dari http://repository.unej.ac.id/hand le/123456789/19713 Di akses 12 februari 2015. Jam 20.20 WIB.

Kuncoro, Budi Eko. 2011. Sukses Budi Daya Ikan Hias Air Tawar. Yogyakarta : Lily Publisher.

Notoatmodjo, Soekidjo. 2012. Metodologi Penelitian Kesehatan. Jakarta : Rineka Cipta.

Sitanggang Maloedyn, Priguna Enggan, 2009. Mencetak Cupang Jawaran Kontes. Jakarta : PT. Agro Media Pustaka.

Sutanto, Heru. 2000. Maanvis.Yogyakarta : KANISIUS.

Sembel,D.T., 2010. Pengendalian Hayati. Yogyakarta : Andi Offiset. 
Soedarjo. 2010. Demam Berdarah Dengue ( Dengue Hermorargik Fever). Jakarta : CV Sagung Seto.

Tarihoran Wati Hijra, 2006. Perbedaan Ikan Cupang Hias (betta splendens crown tail) dan Ikan Hias Maanvis (Pterophyllum altum)Sebagai Predator Larva. Skripsi Fakultas Kesehatan Masyarakat Universitas Sumatera Utara Medan.
Utama Candra, 2010. Tingkat Predasi Ikan Mujair ( Oreochromis Mossambicus) Terhadap larva nyamuk Aedes Aegypti. Skripsi Jurusan Pendidikan Widoyono. 2011. Penyakit Tropis : Epidemiologi, penularan, pencegahan dan pemberantasannya. Jakarta : Erlangga. 